\title{
QUALIDADE DOS GRÃOS DE SOJA EM FUNÇÃO DAS CONDIÇÕES DE ARMAZENAMENTO ${ }^{1}$
}

\author{
Ernandes Rodrigues de Alencar ${ }^{2}$, Lêda Rita D'Antonino Faroni ${ }^{3}$, Adilio Flauzino de Lacerda \\ Filho $^{4}$, Laíne Garcia Ferreira ${ }^{5}$, Manuela Ribas Meneghitti ${ }^{6}$
}

\begin{abstract}
RESUMO
Objetivou-se com este trabalho avaliar a qualidade de soja armazenada em diferentes condições. Grãos de soja foram colhidos com $18,0 \pm 0,2 \%$ b.u. de teor de água e secos até aproximadamente 11 , 13 e $15 \%$ b.u. Em seguida, os grãos foram armazenados a 20,30 e $40 \stackrel{\circ}{ } \mathrm{C}$, estabelecendo-se nove diferentes combinações de teor de água e temperatura. A cada 45 dias até 180 dias de armazenamento, foram determinados o teor de água, o percentual de germinação, a condutividade elétrica da solução que continham os grãos, cor dos grãos e massa específica aparente. Com relação a variável condutividade elétrica, somente os grãos armazenados com teor de água de $11,2 \%$ a 20 e $30 \stackrel{\circ}{ } \mathrm{C}$ não apresentaram aumento, verificando-se, portanto, menor deterioração fisiológica. Observouse aumento mais acentuado da condutividade elétrica à medida que se tinha temperatura e teor de água mais elevados. O percentual de germinação diminuiu ao longo do armazenamento, porém a variação foi mais acelerada, assim como na variável condutividade elétrica, nos grãos armazenados com maior teor de água e em temperatura mais elevada. Em geral, a massa específica dos grãos de soja permaneceu constante. $O$ aumento da temperatura e teor de água teve efeito sobre a coloração dos grãos. Concluiu-se que a qualidade da soja é influenciada pelas condições de armazenagem e que combinações de temperatura e teores de água mais elevados intensificam a deterioração do produto.
\end{abstract}

Palavras-chaves: Perdas qualitativas, percentual de germinação, condutividade elétrica, coloração.

\section{ABSTRACT \\ Quality of soybean grains as affected by storage conditions}

The objective of this study was to determine the influence of storage conditions on the quality of soybean grains. The grains were harvested at about $18.0 \pm 0.2 \%$ w.b moisture content and then dried to about 11,13 or $15 \%$ w.b. The grains at each moisture content were stored at 20,30 or $40 \stackrel{\circ}{\circ}$, thus establishing nine combinations of grain moisture and storage temperature. The samples were withdrawn for 180 days at 45 -day interval to determine moisture content, percent seed germination, the electrical conductivity of the grain leachate, grain color and apparent specific grain mass. The electrical conductivity of leachates from grains at $11.2 \%$ moisture content and stored at 20 or $30^{\circ} \mathrm{C}$ did not change during the storage period, suggesting less physiological deterioration, but increased considerably at higher moisture contents and temperature. The percent germination decreased during the storage period, but like electrical conductivity, it was more rapid in high moisture grains stored at higher temperatures. In general, the apparent specific mass remained constant. The temperature and moisture content affected grain color. It was concluded that quality of soybean is influenced by storage conditions and that high temperature-moisture combination intensify product deterioration.

Keywords: Qualitative loss, percent germination, electrical conductivity, coloration.

\footnotetext{
Recebido para publicação em 24.04.2007

${ }^{1}$ Parte da Tese de Mestrado em Engenharia Agrícola, do primeiro autor, apresentada a Universidade Federal de Viçosa, Viçosa, MG.

${ }_{2}^{2}$ Doutorando em Eng. Agrícola, Depto. de Engenharia Agrícola, Universidade Federal de Viçosa, Viçosa, MG, eg40942@ vicosa.ufv.br

${ }^{3}$ Prof $^{a}$. Associada, Depto. de Eng. Agrícola, Universidade Federal de Viçosa, Viçosa, MG, lfaroni@ ufv.br

${ }^{4}$ Prof. Associado, Depto. de Engenharia Agrícola, Universidade Federal de Viçosa, Viçosa, MG, alacerda@ufv.br

${ }^{5}$ Bolsista de Iniciação Científica do CNPq, Depto. de Engenharia Agrícola, Univ. Federal de Viçosa, Viçosa, MG, lainegafe@ yahoo.com.br

${ }^{6}$ Bolsista de Iniciação Científica da FAPEMIG, Depto. de Engenharia Agrícola, UFV, Viçosa, MG, manuelameneghitti@ yahoo.com.br
} 


\section{INTRODUÇÃO}

Estima-se que a safra de grãos 2006/07 no Brasil seja de cerca de 127 milhões de toneladas, um recorde para a agricultura brasileira (BRASIL, 2007). Desse total, a soja deve contribuir com cerca de $44 \%$ da produção nacional. Entretanto, cada vez mais, é necessário que se tenha produto de qualidade no mercado, pois a qualidade dos grãos é um importante parâmetro para comercialização e processamento, podendo afetar o valor do produto.

A busca por qualidade dos grãos e seus subprodutos deve ser prioridade dos produtores, processadores e para os distribuidores desses produtos. Segundo BROOKER et al. (1992), as principais características que determinam a qualidade dos grãos são: teor de água baixo e uniforme; percentuais reduzidos de material estranho, de descoloração, de susceptibilidade à quebra, de danos pelo calor (trincas internas), danos causados por insetos e fungos; valores elevados de massa específica, concentração de óleos e proteínas e viabilidade. Alguns fatores podem afetar estas características como as condições ambientais durante a formação dos grãos ainda na planta, época e sistema de colheita, sistema de secagem, técnicas de armazenamento, transporte e características da espécie e da variedade.

A massa de grãos é um sistema ecológico em que a deterioração é resultado da interação entre variáveis físicas, químicas e biológicas (externas e internas). O índice de deterioração depende da taxa de variação dessas variáveis, que são afetadas diretamente pela temperatura e teor de água, e ainda pela inter-relação delas com o grão e com a estrutura de armazenagem (SINHA e MUIR, 1973). DORWORTH e CHRISTENSEN (1968) armazenaram soja com teores de água de $12,1, \quad 14,7, \quad 16,5$ e $18,3 \%$ b.u., nas temperaturas de $15,20,25$ e $30{ }^{\circ} \mathrm{C}$ e verificaram aumento gradual do teor de água dos grãos armazenados com 16,5 e $18,3 \%$ b.u., provavelmente pela água metabólica produzida pelo desenvolvimento de fungos. Ao final de 20 a 24 semanas, os autores observaram que os teores de água apresentavam valores acima dos iniciais, com diferença absoluta de $1 \%$.

De acordo com ABBA e LOVATO (1999), o armazenamento de grãos em ambiente natural em regiões tropicais apresenta maiores problemas em decorrência das condições de temperatura e umidade relativa, se comparado com as regiões de clima temperado ou frio. Os parâmetros temperatura e umidade relativa, durante 0 armazenamento, são determinantes no processo de perda de viabilidade das sementes, alterações na coloração e composição do produto (WHIGHAM e MINOR, 1978; LIU, 1997; LACERDA et al., 2003). Para CLARK e SNYDER (1991), o produto armazenado sofre, naturalmente, redução de vigor e de germinação durante o armazenamento, em decorrência da peroxidação de lipídios. Em regiões tropicais, como as do Brasil, onde são observadas temperaturas ambientes de armazenamento acima de $20 \stackrel{\circ}{ } \mathrm{C}, \quad 0$ decréscimo do percentual de vigor e de germinação é mais acentuado (DHINGRA et al., 2001).

Segundo BURRIS (1980), a rápida deterioração da soja durante 0 armazenamento é influenciada pelo teor de água e temperatura. A deterioração qualitativa de soja armazenada com teores iniciais de água entre 9,8 e $13,8 \%$ b.u., em condições tropicais ( $30^{\circ} \mathrm{C}$ e $82 \%$ UR), foi simulada por LOCHER e BUCHELI (1998). Esses autores verificaram acentuada diminuição do percentual de germinação entre 5 e 9 meses de armazenamento, sendo este comportamento mais acentuado nas sementes com maior teor inicial de água. $\mathrm{O}$ efeito da temperatura e umidade relativa na viabilidade de milho foi estudado por ABBA e LOVATO (1999), que armazenaram sementes com $10,5 \%$ b.u. a $30{ }^{\circ} \mathrm{C}$ e $95 \%$ de U.R. Verificaram perda da capacidade germinativa do milho após 42 dias de armazenamento. BHATTACHARYA e RAHA (2002) estudaram as alterações da soja e do milho armazenado com teores de água de 14,0 e $9,7 \%$ b.u., respectivamente, na presença de diferentes espécies de fungos. 
O percentual de germinação da soja e do milho após 10 e 12 meses de armazenamento foi de zero e $4 \%$, respectivamente. GUNGADURDOSS (2003), estudando a viabilidade de sementes de soja em diferentes condições de armazenamento concluiu que o fator temperatura foi predominante na manutenção da viabilidade das sementes de soja. Decréscimo significativo do percentual de germinação devido a interação entre temperatura, conteúdo de água e tempo de armazenagem também foi verificado por PRONYC et al. (2006) em sementes de canola.

Em vista do exposto, objetivou-se com este trabalho avaliar a qualidade da soja armazenada em diferentes combinações de teores de água e temperatura.

\section{MATERIAIS E MÉTODOS}

O trabalho foi realizado no Laboratório de Pré-Processamento e Armazenamento de Produtos Agrícolas do Departamento de Engenharia Agrícola - DEA, na Universidade Federal de Viçosa.

Foram utilizados grãos de soja (Glycine $\max (\mathrm{L}$.) MERRILL) originados do Distrito de Almeida Campos, Nova Ponte, MG. Os grãos, colhidos com teor de água $18 \pm 0,2 \%$ $\%$, foram secos em secador de camada fixa com ar natural, até teores de água de $11,2,12,8$ e $14,8 \%$ b.u.

Após a secagem, os grãos foram acondicionados em recipientes de plástico de aproximadamente $3,00 \quad \mathrm{~L}$ e armazenados em câmaras do tipo B.O.D., nas temperaturas de 20,30 e $40^{\circ} \mathrm{C}$, dispostas em sala climatizada de tal forma que possíveis oscilações da temperatura do ar ambiente não afetassem os valores de temperatura do ar dentro das câmaras. Para garantir o mesmo teor de água dos grãos de soja durante o armazenamento em diferentes temperaturas, a umidade relativa de equilíbrio, previamente calculada pelo modelo de Chung-Pfost (NAVARRO e NOYES, 2001) para cada combinação de temperatura e teor de água (Quadro 1), foi controlada dentro de cada
B.O.D. A manutenção da umidade relativa nos índices desejados foi realizada pela reposição de água em uma bandeja com área previamente estabelecida através de ensaios preliminares, colocada no interior de cada câmara. Foi instalado um depósito externo de água para a manutenção do volume de água, interligado à bandeja através de mangueiras de PVC e uma válvula solenóide que era acionada, em função do valor da umidade relativa medida pelo sensor e registrada pelo sistema de aquisição de dados.O monitoramento e aquisição de dados de temperatura e umidade relativa foi realizado por meio de um sistema computacional denominado 1-wire ${ }^{T M}$.

Durante 180 dias de armazenamento, em intervalos regulares de 45 dias, foram realizadas as seguintes análises: teor de água, germinação e condutividade elétrica e coloração dos grãos.

Para a determinação do teor de água, foi utilizado o método de estufa com circulação forçada de ar, à temperatura de $103 \pm 1{ }^{\circ} \mathrm{C}$, durante 72 horas, em três repetições, conforme recomendações da ASAE (2000), método S352.2.

O percentual de germinação foi obtido de acordo com as Regras para Análise de Sementes (BRASIL, 1992). O teste foi conduzido com quatro repetições de 50 grãos, distribuídos sobre duas folhas de papel filtro umedecido com água destilada na proporção de 2,5 vezes o peso do papel substrato, a $25^{\circ} \mathrm{C}$. A contagem final foi realizada aos oito dias, considerandose as plântulas normais. Os dados foram expressos em percentagem média de germinação.

A condutividade elétrica (CE) da solução contendo os grãos de soja foi feita utilizando-se o "Sistema de Copo" ou "Condutividade de Massa" (VIEIRA et al., 2001), tendo como finalidade avaliar o aumento da permeabilidade da membrana, à medida que o grão se deteriora. Este método baseia-se na modificação da resistência elétrica causada pela lixiviação de eletrólitos dos tecidos dos grãos para a solução em que estes foram imersos. 
Os testes foram realizados em três repetições, com 50 grãos para cada tratamento, ao longo do período de armazenagem. Os grãos foram pesados em balança com precisão de 0,01 grama e colocados em copos de plástico de $200 \mathrm{~mL}$, aos quais foram adicionados $75 \mathrm{~mL}$ de água deionizada. Em seguida, os copos foram colocados em uma câmara climática do tipo B.O.D., em temperatura de $25^{\circ} \mathrm{C}$, durante 24 horas. Imediatamente após este período, os copos foram retirados da câmara para medições da condutividade elétrica da solução que contém os grãos. As leituras foram feitas em medidor de condutividade elétrica da marca Tecnopon, modelo CA-150, com ajuste para compensação de temperatura e eletrodo, com constante da célula de $1 \mu \mathrm{S} \mathrm{cm}^{-1}$. Antes de realizar as leituras, o aparelho era calibrado com uma solução-padrão de cloreto de sódio, de condutividade elétrica conhecida, a $25{ }^{\circ} \mathrm{C}$. $\mathrm{O}$ valor da condutividade elétrica ( $\mu S \mathrm{~cm}^{-1}$ ) fornecido pelo aparelho foi dividido pela massa de matéria seca dos grãos (g), obtendo-se

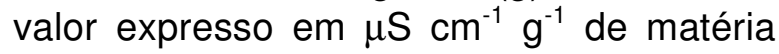
seca.

A massa específica aparente (MEA) dos grãos de soja foi medida em uma balança de peso hectolítrico de $1 / 4$ de litro utilizando-se grãos limpos, ou seja, os grãos retidos na peneira de 3,00 mm de diâmetro, de acordo com a Portaria № 262, de 23/1/.1983, do Ministério da Agricultura Pecuária e Abastecimento, publicada no D.O.U. de 25/11/1983 (BRASIL, 1983).

A quantificação da cor dos grãos de soja foi efetuada com 0 auxílio do colorímetro triestímulo ColorQuest ${ }^{\mathrm{TM}}$ II. Os testes foram realizados em três repetições, obtendo-se, então, os valores das coordenadas $\mathbf{L}$ (luminosidade), $\mathbf{a}$ e $\mathbf{b}$ do sistema Hunter para avaliação da cor. Com os valores das coordenadas $\mathbf{L}$, $\mathbf{a}$ e $\mathbf{b}$ foi possível gerar parâmetros relacionados a tonalidade $\mathbf{h}$ (Equação 1) e a saturação da cor C (Equação 2) (LITTLE, 1975, FRANCIS, 1975, MCLELLAN et al., 1995, MASKAN, 2001).

$$
\mathrm{h}=\operatorname{arctang}(\mathrm{b} / \mathrm{a})
$$

$C=\sqrt{\left(a^{2}+b^{2}\right)}$

em que,

$\mathrm{h}=$ tonalidade da cor;

$\mathrm{C}$ = saturação da cor ou croma;

$L=$ mensurável em termos de intensidade de branco a preto;

$a=$ mensurável em termos de intensidade de vermelho e verde; e

$b=$ mensurável em termos de intensidade de amarelo e azul.

O experimento foi montado em delineamento inteiramente casualizado, em parcelas subdivididas, com três repetições. Os tratamentos, combinações de temperatura (20, 30 e $\left.40^{\circ} \mathrm{C}\right)$ e teor de água $(11,2,12,8$ e $14,8 \%)$ foram alocados na parcela, enquanto que a subparcela correspondeu ao período de armazenamento $(0,45,90,135,180$ dias $)$, fazendo com que a estrutura de tratamentos correspondesse ao fatorial $3 \times 3 \times 5$. Inicialmente foi realizada análise de variância considerando medidas repetidas, para determinação da melhor estrutura de covariância residual. Utilizou-se estatística descritiva para as variáveis percentual de germinação, massa específica a aparente e coloração dos grãos e análise de regressão para condutividade elétrica.

\section{RESULTADOS E DISCUSSÃO}

No Quadro 2, apresentam-se os valores de teor de água de equilíbrio dos grãos de soja armazenados durante 180 dias, em três temperaturas e respectivos valores de umidade relativa de equilíbrio. Em geral, os teores de água dos grãos permaneceram praticamente constantes, com desvio padrão máximo de 0,4 , exceto para os grãos armazenados com conteúdo de água de $14,8 \%$ b.u. a $30{ }^{\circ} \mathrm{C}$ e $83 \%$ de URe e 12,8 e $14,8 \%$ b.u. na temperatura de $40 \stackrel{\circ}{ } \mathrm{C}$ e URe de 80 e $86 \%$, respectivamente. Atribuiu-se o aumento do teor de água à atividade respiratória dos grãos e da microflora a eles associada, embora a taxa respiratória dos grãos seja, geralmente, menos intensa que a dos microorganismos (POMERANZ, 1974, MUIR e WHITE, 2000). 
De acordo com os resultados da análise de variância, pelo teste $\mathrm{F}$ a $5 \%$ de probabilidade, houve diferença significativa do percentual de germinação devido a interação tripla entre conteúdo de água, temperatura e período de armazenamento. Os valores médios de percentual de germinação dos grãos de soja armazenados com diferentes teores de água para cada temperatura durante 0 armazenamento encontram-se no Quadro 3.

A $20 \stackrel{\circ}{ } \mathrm{C}$, a redução do potencial de germinação foi mais acentuada para o teor de água de $14,8 \%$ b.u., comparando-se com 11,2 e $12,8 \%$ b.u., para as mesmas condições e tempo de armazenagem. Após 135 dias de armazenamento, os grãos com $14,8 \%$ b.u. a 20 ${ }^{\circ} \mathrm{C}$ não germinaram. Nas temperaturas de $30 \mathrm{e}$ $40{ }^{\circ} \mathrm{C}$, a redução foi mais acentuada à medida que se elevou o teor de água grãos. DORWORTH e CHRISTENSEN (1968) obtiveram resultados semelhantes quando armazenaram soja com quatro teores de água e quatro temperaturas diferentes, embora não tenham controlado a umidade relativa ao longo do armazenamento.

A interação entre teor de água, temperatura e período de armazenamento demonstrou efeito significativo sobre a condutividade elétrica da solução que continha os grãos de soja, conforme os resultados da análise de variância, pelo teste $F$ a $5 \%$ de probabilidade. Apresentam-se na Figura 1 , as curvas de regressão de condutividade elétrica correspondentes às soluções que continham os grãos armazenados com teores de água de $11,2,12,8$ e $14,8 \%$ b.u. nas temperaturas de 20,30 e $40^{\circ} \mathrm{C}$.

No Quadro 4 estão apresentadas as equações de regressão ajustadas e os seus respectivos coeficientes de determinação, que relacionam condutividade elétrica da solução que continha os grãos de soja em três teores de água e o período de armazenamento para cada temperatura.

Observa-se que na temperatura de $20{ }^{\circ} \mathrm{C}$ (Figura 1A) somente os grãos armazenados com teor de água de $14,8 \%$ b.u. apresentaram aumento da condutividade elétrica $e$, conseqüentemente, redução da qualidade fisiológica. $\mathrm{O}$ aumento da condutividade elétrica foi mais expressivo à medida que se aumentou a temperatura e o teor de água dos grãos (Figuras 1B e C), embora na temperatura de 40 ${ }^{\circ} \mathrm{C}$, independentemente do teor de água dos grãos, os resultados da condutividade elétrica da solução que continha esses grãos apresentaram elevação durante o período de armazenamento. Infere-se, com isso, que temperaturas e teores de água mais altos contribuem para o aumento da degradação dos grãos observada pela desnaturação da membrana celular.

Diversos autores utilizaram a condutividade elétrica como parâmetro qualitativo de grãos. A condutividade elétrica foi utilizada por KRITTIGAMAS et al. (2001) como na determinação do vigor em soja armazenada. Os autores observaram aumento significativo deste parâmetro e, conseqüentemente, perda de vigor dos grãos ao longo de 180 dias. KRISHNAN et al. (2004) estudou as características termodinâmicas da soja durante 0 armazenamento sob condições de envelhecimento acelerado, e também verificaram valores médios maiores de condutividade elétrica da solução que continha os grãos à medida que se utilizavam temperaturas mais elevadas ao longo do período de armazenamento. A influência da interação teor de água, temperatura e período de armazenamento na qualidade da soja foi analisada por YAJA et al. (2005). Os autores armazenaram soja com três teores de água, 6 , 8,10 e $12 \%$ b.u., a $15,20,25,35^{\circ} \mathrm{C}$, e obtiveram acréscimo significativo da condutividade elétrica que continham os grãos de soja após 120 dias.

Observou-se que, independentemente do teor de água, a massa específica aparente dos grãos de soja permaneceu praticamente constante na temperatura de $20 \stackrel{\circ}{\circ}$. Resultado semelhante foi observado para a temperatura de $30 \stackrel{\circ}{ } \mathrm{C}$, exceto para os grãos armazenados com $12,8 \%$ b.u., a partir de 90 dias de armazenamento, com redução de $2,6 \%$ após 180 dias. Na soja armazenada com teor de água de $12,8 \%$ a $30{ }^{\circ} \mathrm{C}$ foi constatada a presença de grande quantidade de grãos danificados por insetos-praga da Ordem Lepdoptera, Plodia Interpunctella e Sitotroga cerealella, razão da redução da massa específica aparente. Uma provável explicação da ocorrência de insetos-praga é que os grãos já vieram infestados do campo. Para a temperatura de $40{ }^{\circ} \mathrm{C}$, observou-se redução na massa específica aparente dos grãos de soja armazenados com teor de água de 14,8\% b.u., a partir de 45 dias de armazenamento, com redução de 3,3\% após 180 dias. 
Esse resultado confirma o incremento da atividade metabólica dos grãos devido o elevado teor de água (Tabela 2), na temperatura de $40 \stackrel{\circ}{ } \mathrm{C}$. Por esse motivo, verificou-se desenvolvimento acelerado de fungos e após 180 dias detectou-se alta incidência de Aspergillus glaucus (87\%).

Apresentam-se, na Figura 2, os valores médios da tonalidade de cor (h) dos grãos armazenados com três teores de água $(11,2$, 12,8 e $14,8 \%$ b.u.) à temperatura de 20,30 e 40 ํ. Em geral, os grãos de soja, independentemente do teor de água e da temperatura, apresentaram acréscimo na tonalidade da cor, ao longo do período de armazenamento. $O$ aumento da tonalidade foi mais acentuado nos primeiros 90 dias, principalmente às temperaturas de 20 e 30 ${ }^{\circ} \mathrm{C}$ (Figuras 2 e B). Na temperatura de $40{ }^{\circ} \mathrm{C}$ (Figura 2C), embora tenha ocorrido alteração da tonalidade dos grãos, ao contrário do esperado foi menos intensa, destacando-se ainda que os grãos armazenados com teor de água de 14,8\% b.u. perderam sua tonalidade a partir de 135 dias de armazenamento. A redução da tonalidade está associada ao escurecimento da soja e confirma o desenvolvimento de fungos e, conseqüentemente, a elevação do percentual de ardidos.

Encontram-se na Figura 3 os valores médios de saturação da cor dos grãos de soja armazenados com teores de água de $11,2,12,8$ e $14,8 \%$ b.u., a 20,30 e $40 \stackrel{\circ}{\circ}$. Observou-se decréscimo nos valores de saturação de cor em todas as temperaturas, embora a diminuição tenha sido mais acentuada para os grãos armazenados com teor de água $14,8 \%$ b.u. Os grãos armazenados com teores de água de 11,2 e $12,8 \%$ b.u. apresentaram comportamento semelhante as temperaturas de 20 e $30 \stackrel{\circ}{\circ}$ (Figuras $3 \mathrm{~A}$ e B). Todavia, na temperatura de $40 \stackrel{\circ}{ } \mathrm{C}$ (Figura $3 \mathrm{C}$ ), apenas os grãos armazenados com $11,2 \%$ b.u. apresentaram redução menos acentuada da cromaticidade. Isso, segundo MENDONÇA et al. (2003), expressa a intensidade da cor, ou seja, a saturação em termos de pigmentos ou valores de croma próximos a zero representam cores neutras (cinza) e valores próximos a 60 expressam cores vívidas. Assim como na tonalidade, a redução do croma está associada ao escurecimento da soja.

\section{CONCLUSÕES}

Concluiu-se que a qualidade da soja é influenciada pelas condições de armazenagem e que combinações de temperatura e teores de água mais elevados intensificam a deterioração do produto; o armazenamento de soja não é recomendado nas seguintes combinações de teor de água e temperatura: $11,0 \%$ b.u. a $40{ }^{\circ} \mathrm{C} ; 13,0 \%$ b.u. e temperaturas superiores de $30{ }^{\circ} \mathrm{C}$; e $15,0 \%$ b.u. e temperaturas superiores a 20 C; e é possível armazenar, a $20{ }^{\circ} \mathrm{C}$, soja com teor de água de até $13,0 \%$ b.u. sem risco de deterioração por até 180 dias.

\section{REFERÊNCIAS BIBLIOGRÁFICAS}

ABBA, E.J.; LOVATO, A. Effect of seed storage temperature and relative humidity on maize (Zea mays L.) seed viability and vigour. Seed Science and Technology, Zurich, v. 27, p. 101-114, 1999.

ASAE. Moisture measurement -- unground grain and seeds. In: Standards, 2000. St. Joseph: American Society of Agricultural Engineers. $563 \mathrm{p}$.

BHATTACHARYA, K.; RAHA, S. Deteriorative changes of maize, groundnut and soybean seeds by fungi in storage. Mycopathologia, Springer, v. 155, p. 135-141, 2002.

BRASIL. Ministério da Agricultura, Pecuária e Abastecimento. Portaria no 262 de 23.11.1983, D.O.U. 25.11.1983, Brasília/DF.

\section{BRASIL. Regras para Análise de \\ Sementes. Brasília: Ministério da Agricultura, 1992. 365 p.}

\section{BRASIL. Ministério da Agricultura, Pecuária e Abastecimento. Companhia Nacional de Abastecimento - CONAB. Estimativa de produção de grãos da safra 2006/2007. Disponível em: www.conab.gov.br/conabweb/download/safra/6levs afra.pdf. Acesso em: 02 março 2007.}


BROOKER, D.B.; BAKKER-ARKEMA, F.W.; HALL, C.W. Drying and storage of grains and oilseeds. New York: Van Nostrand Reinhold, 1992. 450 p.

BURRIS, J.S. Maintenance of soybean seed quality in storage as influenced by moisture, temperature and genotype. lowa State Journal of Research, v. 54 , p. $377-389$, 1980.

CLARK, P.K.; SNYDER, H.E. Hidroperoxide formation in soybean seeds during storage. Journal of the American Oil Chemists' Society, Champaign, v. 68 , n. 5, p. 346-347, 1991.

DHINGRA, O.D.; MIZUBUTI, E.S.G.; NAPOLEÃO, I.T.; JHAM, G. Free fatty acid accumulation and quality loss of stored soybean seeds invaded by Aspergillus ruber. Seed Science and Technology, Zurich, v. 29, p. 193-203, 2001.

DORWORTH, C.E.; CHRISTENSEN, C.M. Influence of moisture content, temperature, and storage time upon changes in fungus flora, germinability, and fat acidity values of soybeans. Phytopathology, St. Paul, v. 58, p. 1457-1459, 1968.

FRANCIS, F.J. The origin of $\tan ^{-1} a / b$. Journal of Food Science, Chicago, v. 40, p. 412, 1975.

GUNGADURDOSS, M. Improvement of seed viability of vegetable soybean (Glycine max (L) Merrill). In: Food and Agricultural Research Council, 2003, Réduit, Mauritius. Proceedings...: Réduit, Mauritius: LALOUETTE, J.A., BACHRAZ (Eds.), 2003. 117-123.

KRISHNAN, P.; NAGARAJAN, S.; MOHARIR, A.V. Thermodynamic characterization of seed deterioration during storage under accelerated ageing conditions. Biosystems Engineering, London, v. 89, n. 4, p. 425-433, 2004.
KRITTIGAMAS, N.; VEARASILP, S.; THANAPORNPOONPONG, $S$; ; SURIYONGA, S.; PAOBLEK, S.; PAWELZIKC, E. Investigation of postharvest soybean seed storability after passing the different steps of processing. In: Conference on International Agricultural Research for Development. 5th, 2001, Bonn, Germany. Proceedings... Bonn, Germany: ASCH, F., BECKER, M. (Eds.), 2001. 1-4.

LACERDA, A.D.S.; LAZARINI, E.; SÁ, M.E.; FILHO, W.V.V. Armazenamento de sementes de soja dessecadas e avaliação da qualidade fisiológica, bioquímica e sanitária. Revista Brasileira de Sementes, Pelotas, v. 25, n. 2, p. 97-105, 2003.

LOCHER, R.; BUCHELI, P. Comparison of soluble sugar degradation in soybean seed under simulated tropical storage conditions. Crop Science, Madison, v. 38, p. 12291235, 1998.

LITTLE, A. Off on a tangent. Journal of Food Science, Chicago, v. 40, p. 410-411, 1975.

LIU, K. Soybeans: chemistry, technology and utilization. New York: Chapman \& Hall, 1997. 532p.

MASKAN, M. Kinetics of colour change of kiwifruits during hot air and microwave drying. Journal of Food Engineering, Kidlington, v. 48, p. 169-175, 2001.

MCLELLAN, M.R.; LIND, L.R.; KIME, R.W. Hue angle determinations and stastistical analysis for multiquadrant hunter $\mathrm{L}, \mathrm{a}, \mathrm{b}$ data. Journal of Food Quality, Trumbull, v. 18, n. 3, p. 235-240, 1995.

MENDONÇA, K.; JACOMINO, A.P.; MELHEM, T.X.; KLUGE, R.A. Concentração de etileno e tempo de exposição para desverdecimento de limão 'siciliano'. Brazilian Journal of Food Technology, Campinas, v. 26, n.2, p. 179-183, 2003. 
MUIR, W.E.; WHITE, N.D.G. Microorganisms in stored grain. In: Muir, W.E. (Ed.) Grain Preservation Biosystems. Manitoba, p. 1-17, 2000.

NAVARRO, S.; NOYES, S.T. The Mechanics and Physics of Modern Grain Aeration Management. Boca Raton: CRC Press, 2001. $672 \mathrm{p}$.

POMERANZ, Y. Biochemical, functional, and nutritive changes during storage. In: CHRISTENSEN, C.M. (Ed.) Storage of cereal grains and their products. St. Paul, 1974, p. 56-114.

PRONYK, C.; ABRAMSON, D.; MUIR, W.E.; WHITE, N.D.G. Correlation of total ergosterol levels in stored canola with fungal deterioration. Journal of Stored Products Research, Oxford, v. 42, p. 162-172, 2006.

SINHA, R. N.; MUIR, W. E. Grain storage: part of a system. Avi Pub. Co.: Westport, CN, 1973. 481 p.
VIEIRA, R.D.; TEKRONY, D.M.; EGLI, D.B.; RUCKER, M. Electrical conductivity of soybean seeds after storage in several environments. Seed Science and Technology, Zurich, v. 29, p. 599-608, 2001.

WHIGHAM, D.K.; MINOR, H.C. Agronomic characteristics and environmental stress. In: NORMAN, A.G. (ed.) Soybean physiology, agronomy and utilization. New York, 1978, p. 77-118.

YAJA, J.; PAWELZIK, E.; VEARASILP, S. Prediction of soybean seed quality in relation to seed moisture content and storage temperature. In: Conference on International Agricultural Research for Development. 8th, 2005, Stuttgart-Hohenheim, Germany. Proceedings... Stuttgart-Hohenheim, Germany: TIELKES, E.; HÜLSEBUSCH, C.; HÄUSER, I.; DEININGER, A.; BECKER, K. (Eds.), 2005. 1-4.

\section{QUADROS E FIGURAS}

Quadro 1. Valores de umidade relativa de equilíbrio do ar, para as respectivas combinações de temperatura e teor de água

\begin{tabular}{cccc}
\hline \multirow{2}{*}{ Temperatura (ㅇ) } & \multicolumn{3}{c}{ Teor de água (\%) b.u. } \\
\cline { 2 - 4 } & $\mathbf{1 1 , 2}$ & $\mathbf{1 2 , 8}$ & $\mathbf{1 4 , 8}$ \\
\hline $\mathbf{2 0}$ & 61,0 & 72,0 & 80,0 \\
$\mathbf{3 0}$ & 67,0 & 76,0 & 83,0 \\
$\mathbf{4 0}$ & 71,0 & 80,0 & 86,0 \\
\hline
\end{tabular}

Quadro 2. Valores médios de teor de água de equilíbrio dos grãos de soja armazenados a 20, 30 e $40^{\circ} \mathrm{C}$ durante 180 dias

\begin{tabular}{|c|c|c|c|c|c|c|c|}
\hline \multirow{2}{*}{ Temp. ( $\left.{ }^{\circ} \mathrm{C}\right)$} & \multirow{2}{*}{$\begin{array}{c}\mathrm{UR}_{\mathrm{e}}(\%) \\
61,0\end{array}$} & \multicolumn{5}{|c|}{ Período de armazenamento (dias) } & \multirow{2}{*}{$\frac{\text { Média } \pm \text { DP* }}{10,9 \pm 0,3}$} \\
\hline & & 11,2 & 11,2 & 10,8 & 10,7 & 10,6 & \\
\hline \multirow[t]{3}{*}{20} & 72,0 & 12,8 & 12,6 & 12,8 & 13,2 & 12,9 & $12,9 \pm 0,2$ \\
\hline & 80,0 & 14,8 & 15,0 & 15,6 & 14,8 & 14,7 & $15,0 \pm 0,4$ \\
\hline & 67,0 & 11,2 & 11,3 & 11,1 & 10,5 & 10,6 & $10,9 \pm 0,4$ \\
\hline \multirow[t]{3}{*}{30} & 76,0 & 12,8 & 12,6 & 12,8 & 12,8 & 12,8 & $12,7 \pm 0,1$ \\
\hline & 83,0 & 14,8 & 15,2 & 16,3 & 17,9 & 17,3 & $16,3 \pm 1,4$ \\
\hline & 71,0 & 11,2 & 11,4 & 11,1 & 10,9 & 10,9 & $11,1 \pm 0,2$ \\
\hline \multirow[t]{2}{*}{40} & 80,0 & 12,8 & 13,3 & 13,5 & 15,0 & 14,8 & $13,9 \pm 0,9$ \\
\hline & 86,0 & 14,8 & 15,0 & 17,6 & 17,0 & 16,2 & $16,1 \pm 1,2$ \\
\hline
\end{tabular}

* DP - Desvio padrão 
Quadro 3. Valores médios de percentual de germinação dos grãos de soja com teores de água de $11,2,12,8$ e $14,8 \%$ b.u. nas temperaturas de 20,30 e $40{ }^{\circ} \mathrm{C}$, ao longo do armazenamento

\begin{tabular}{ccccccc}
\hline \multirow{2}{*}{ Temp. (ㄷ) } & $\begin{array}{c}\text { Teor de } \\
\text { água (\%) }\end{array}$ & \multicolumn{5}{c}{ Período de armazenamento (dias) } \\
\cline { 3 - 7 } & $\mathbf{1 1 , 2}$ & 87,3 & 74,6 & 73,6 & 72,7 & 66,3 \\
\multirow{2}{*}{20} & $\mathbf{1 2 , 8}$ & 86,3 & 77,3 & 74,0 & 75,3 & 66,0 \\
& $\mathbf{1 4 , 8}$ & 83,7 & 58,7 & 25,0 & 0 & 0 \\
\hline \multirow{3}{*}{30} & $\mathbf{1 1 , 2}$ & 84,7 & 73,7 & 53,7 & 54,3 & 15,0 \\
& $\mathbf{1 2 , 8}$ & 88,0 & 70,7 & 29,0 & 4,7 & 0 \\
& $\mathbf{1 4 , 8}$ & 85,7 & 16,3 & 0 & 0 & 0 \\
\hline \multirow{3}{*}{$\mathbf{4 0}$} & $\mathbf{1 1 , 2}$ & 88,3 & 40,3 & 0 & 0 & 0 \\
& $\mathbf{1 2 , 8}$ & 93,3 & 0 & 0 & 0 & 0 \\
& $\mathbf{1 4 , 8}$ & 84,3 & 0 & 0 & 0 & 0 \\
\hline
\end{tabular}

Quadro 4. Equações de regressão ajustadas para condutividade elétrica da solução que continha os grãos de soja com teores de água de $11,2,12,8$ e $14,8 \%$ b.u. nas temperaturas de 20,30 e $40{ }^{\circ} \mathrm{C}$ ao longo do período de armazenamento $(\mathrm{X})$, e respectivos coeficientes de determinação

\begin{tabular}{cccccc}
\hline $\begin{array}{c}\text { Temp. } \\
\text { (o-C) }\end{array}$ & $\begin{array}{c}\text { Teor de } \\
\text { água (\%) }\end{array}$ & Equações ajustadas & $\mathbf{R}^{2}$ & $\mathbf{F}$ & Prob. \\
\hline \multirow{2}{*}{$\mathbf{2 0}$} & $\mathbf{1 1 , 2}$ & $\hat{y}=153,4$ & & 0,23 & 0,6366 \\
& $\mathbf{1 2 , 8}$ & $\hat{y}=147,1$ & & 2,48 & 0,1389 \\
& $\mathbf{1 4 , 8}$ & $\hat{y}=149,4-0,2029 X+0,0087 X^{2}$ & 0,89 & 45,54 & $<0,0001$ \\
\hline \multirow{3}{*}{$\mathbf{3 0}$} & $\mathbf{1 1 , 2}$ & $\hat{y}=145,4-0,0403 X$ & 0,91 & 11,19 & $<0,001$ \\
& $\mathbf{1 2 , 8}$ & $\hat{y}=145,5-0,1477+0,0045 X^{2}$ & 0,87 & 40,01 & $<0,0001$ \\
& $\mathbf{1 4 , 8}$ & $\hat{y}=143,7+2,8360 X-0,0056 X^{2}$ & 0,94 & 91,61 & $<0,0001$ \\
\hline \multirow{2}{*}{$\mathbf{4 0}$} & $\mathbf{1 1 , 2}$ & $\hat{y}=159,6-0,4581 X+0,0053 X^{2}$ & 0,97 & 199,31 & $<0,0001$ \\
& $\mathbf{1 2 , 8}$ & $\hat{y}=175,5+3,768 X-1,002 X^{2}$ & 0,88 & 45,45 & $<0,0001$ \\
& $\mathbf{1 4 , 8}$ & $\hat{y}=194,2+4,403 X-1,530 X^{2}$ & 0,84 & 31,67 & $<0,0001$ \\
\hline
\end{tabular}



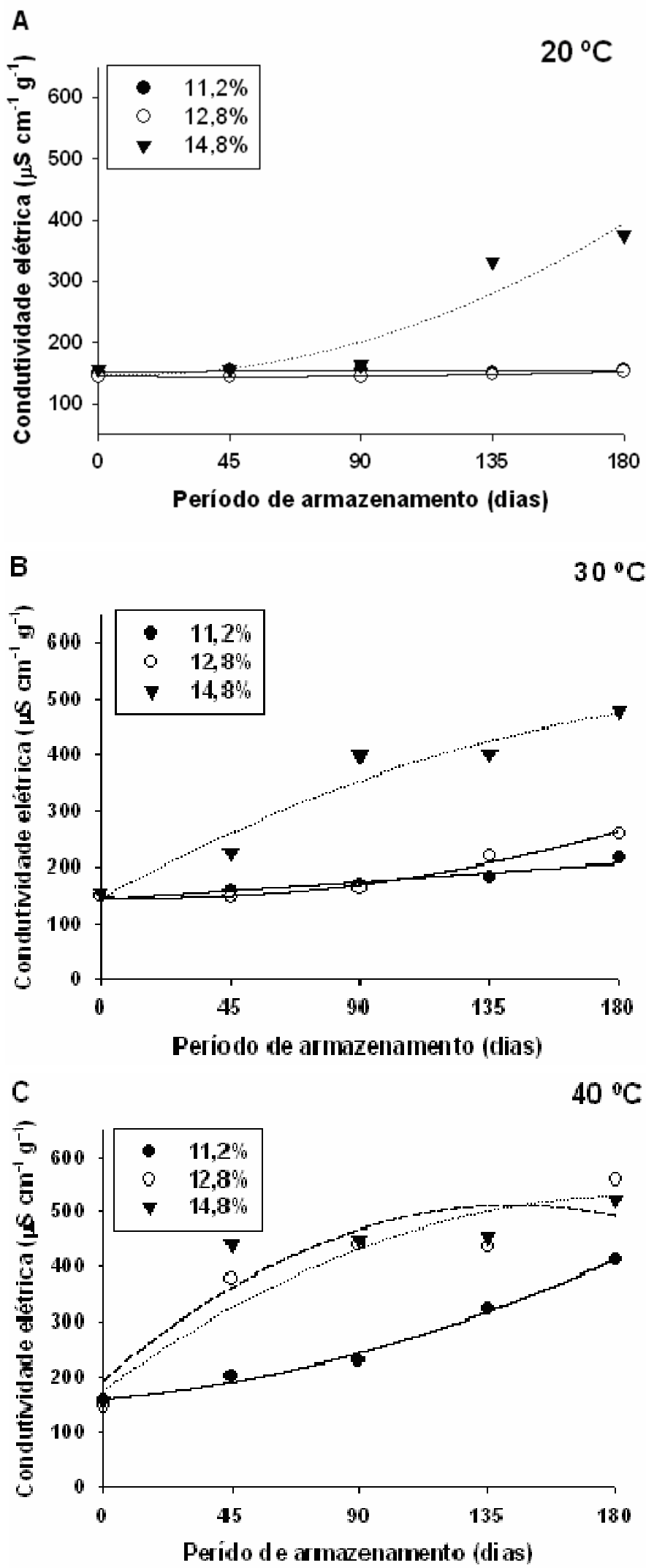

Figura 1. Curvas de regressão da condutividade elétrica $\left(\mu \mathrm{cm}^{-1} \mathrm{~g}^{-1}\right)$ da solução que continha os grãos de soja armazenados com teores de água de 11,2, 12,8 e $14,8 \%$ b.u. nas temperaturas de 20,30 e $40 \stackrel{\circ}{ } \mathrm{C}$. 


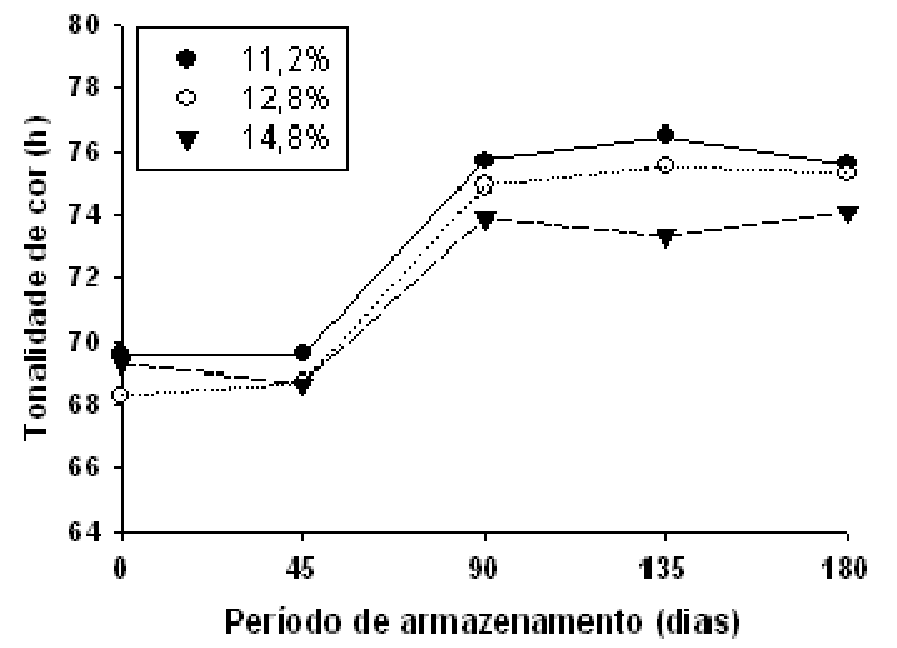

B

$30^{\circ} \mathrm{C}$

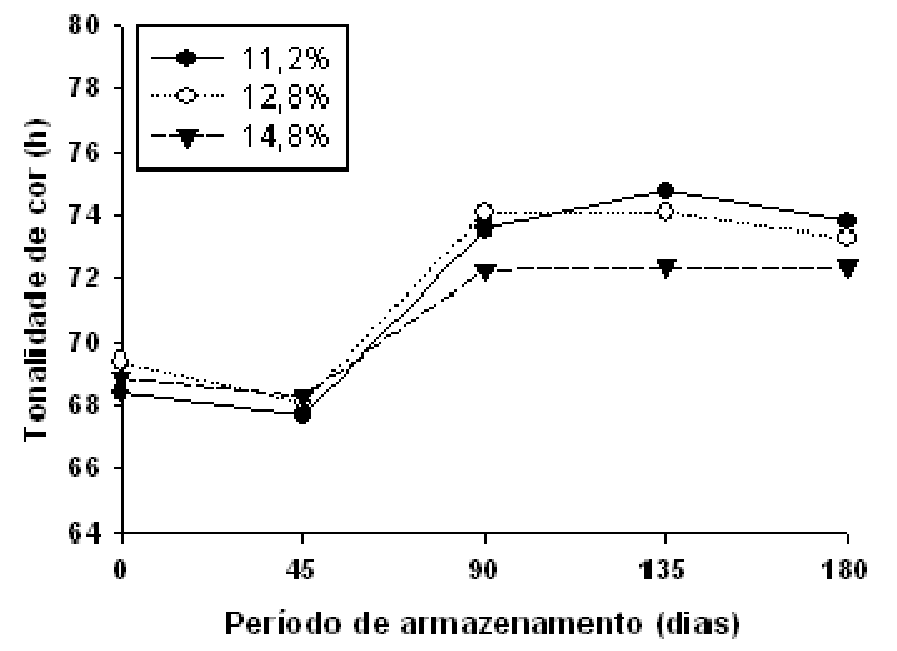

C

$40^{\circ} \mathrm{C}$

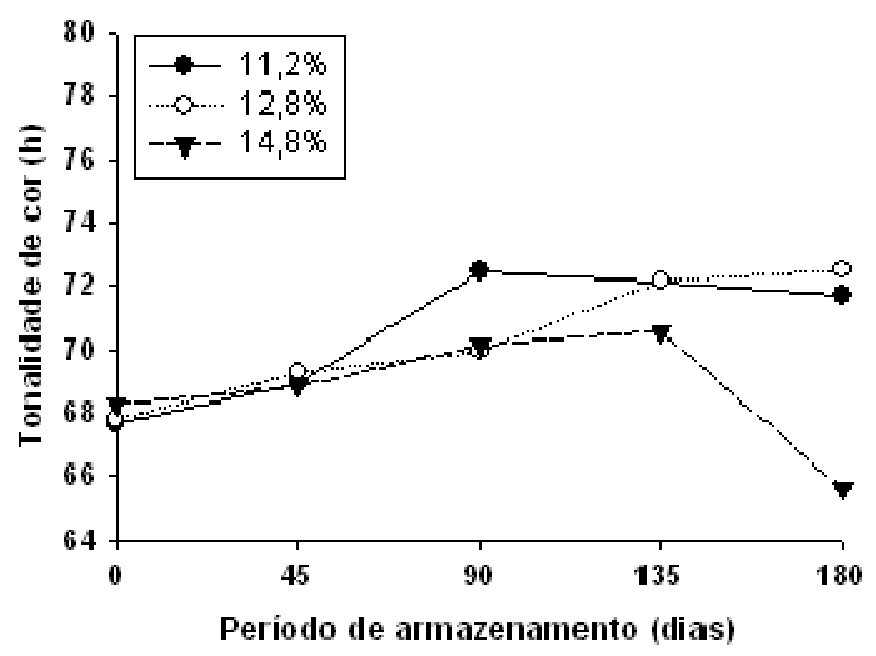

Figura 2. Valores médios de tonalidade de cor (h) de grãos de soja com teores de água de $11,2,12,8$ e $14,8 \%$ b.u. nas temperaturas de 20,30 e $40^{\circ} \mathrm{C}$, ao longo do armazenamento. 


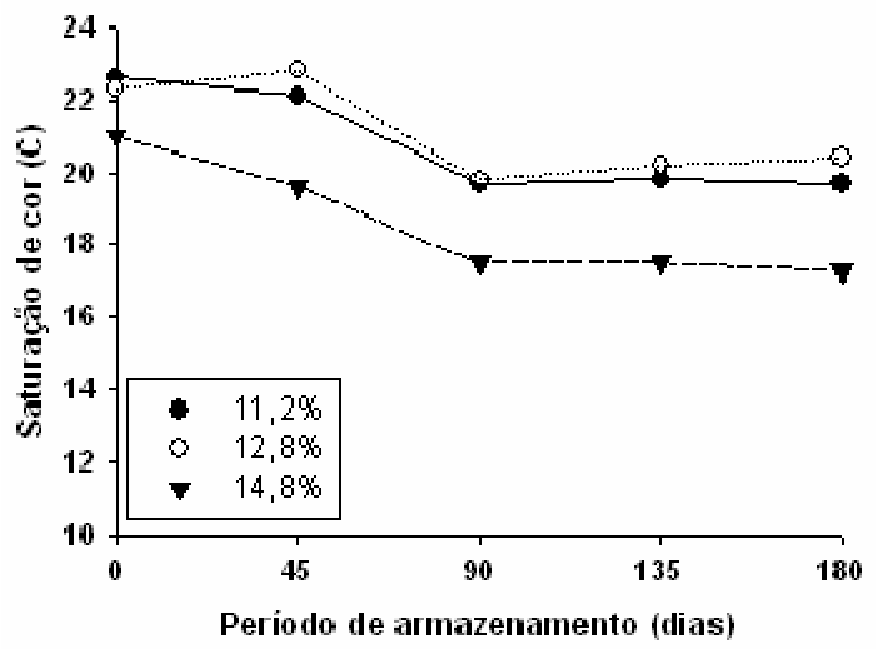

B

$30^{\circ} \mathrm{C}$

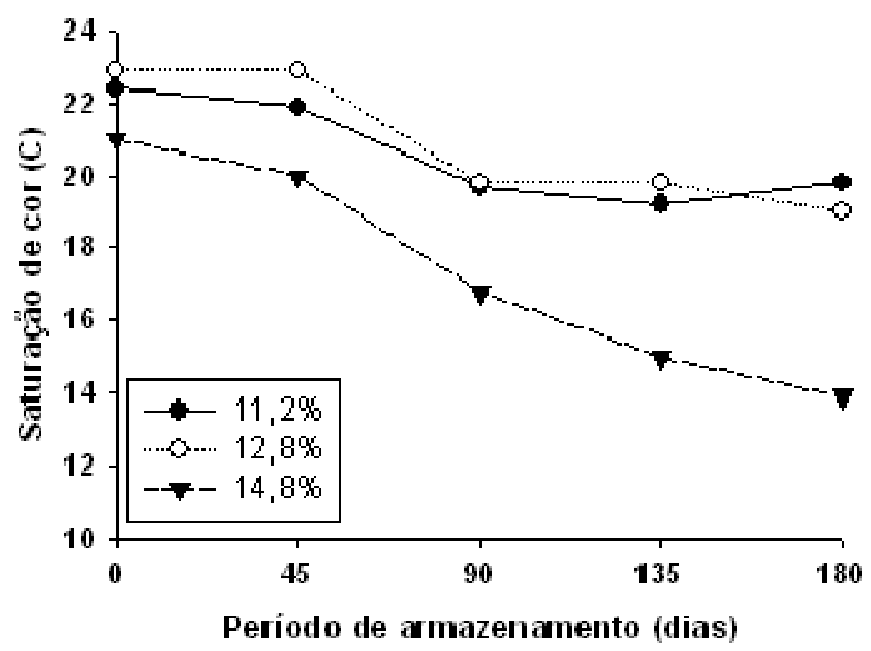

$\mathrm{C}$

$40^{\circ} \mathrm{C}$

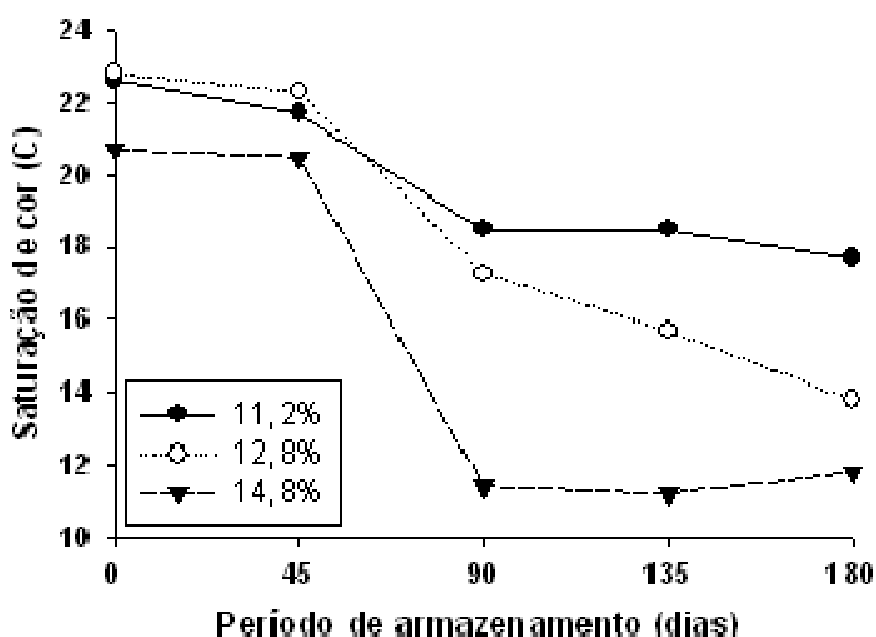

Figura 3. Valores médios de saturação de cor (Croma) de grãos de soja com teores de água de $11,2,12,8$ e $14,8 \%$ b.u. nas temperaturas de 20,30 e $40{ }^{\circ} \mathrm{C}$, ao longo do armazenamento. 